\title{
ANALYSING EGOVERNMENT RESEARCH: CURRENT AREAS AND DIMENSIONS
}

\author{
Demetrios Sarantis \\ United Nations University - Operating Unit on Policy-Driven Electronic Governance \\ Campus de Couros, Rua Vila Flor 166, 4810-445 Guimarães, Portugal
}

\begin{abstract}
In recent years, there has been rapid growth in the volume of research output on the topic of eGovernment. The analysis of the literature reveals significant insights about the evolution of eGovernment research over time, the assessment of which serves as a basis for recommendations for future research on this global phenomenon. To understand this research better, the specific study has selected papers that contribute to the development of eGovernment research through conceptualizations and clarifications of the field, as well as by addressing significant issues and trends. Through reviewing those studies in eGovernment literature this paper categorises the outcomes and identifies three research areas and twenty dimensions in which the research community targets its efforts.
\end{abstract}

\section{KEYWORDS}

eGovernment, eGovernance, eGovernment Research, Dimensions, Areas, Domains

\section{INTRODUCTION}

The topic of eGovernment has arguably attained adequate autonomy to justify an investigation through specialised conferences, journals, books, MSc programs and through the new researchers it has attracted (Y1ldı, 2012; Sarantis et al., 2019). eGovernment research takes place in a range of different types of institutions (Heeks, \& Bailur, 2007). A recent study by the United Nations has shown that many emerging economies are making concrete steps to improve their eGovernment capacity (United Nations, 2016).

From the research side of the discourse there is no single dominant theme in eGovernment (Kankanhalli, Zuiderwijk, \& Tayi, 2017). The field is as diverse as possible and eGovernment research has increasingly highlighted the complexities, interactions, and conflicts intrinsic to the public sector as pivotal for understanding eGovernment (Cordella, \& Iannacci, 2010; Dawes, 2009). This fact highlights the difficulty in capturing a clear path of where the discipline is going, or what factors are driving and affecting research foci (Joseph, 2013).

Thus, there is a need to decompose and scrutinize existing literature to derive pathways in the published articles and develop a coherent and comprehensive research agenda to guide researchers in their pursuit for a better understanding of eGovernment. Because of this remarkable growth and importance of the field, we attempt, in this paper, to review the existing eGovernment research literature and draw conclusions from that reflection about current status and possible future directions. The structure of the paper is as follows. Next section introduces the research method applied while third section reviews identified relative literature. Then, the fourth section illustrates and analyses identified eGovernment research dimensions and sub dimensions. Finally, main conclusions are discussed in the last section.

\section{RESEARCH METHOD}

The exploratory research method applied in this study is based on tracking existing publications as a proxy for the research community's preferences and attribution of importance to different issues and topics within 
eGovernment field. This type of inductive approach has been chosen since authors consider that significant aspects and answers are already embedded in the current eGovernment literature.

To conduct this study, we decided to apply content analysis method and to focus on sources associated specifically with eGovernment, including those associated with existing research domains such as leading information systems (IS) or foremost public administration journals and conferences. The selected sources were those identified as the dominant and most cited eGovernment-specific research outlets after 2010. Ten papers were chosen that were subjected to analysis. We then proceeded to analyse and code identified research elements from all nine papers. The findings from this analysis are laid out below and are discussed in greater detail to fulfil the purpose of understanding the current standing of eGovernment research (Heeks, \& Bailur, 2007). The content of the studies found as a result of this search effort are examined in detail to derive the key elements of eGovernment, which are presented below.

\section{THE STATE OF THE FIELD OF EGOVERNMENT RESEARCH}

Several studies have been conducted to explore eGovernment research agenda. The most recent and relevant identified in this review (Table 1) and they are analysed below.

Table 1. eGovernment Studies Analysed

\begin{tabular}{llll}
\hline$\#$ & Author & Title & Year \\
\hline 1 & Estevez, Janowski & Electronic Governance for Sustainable Development - Conceptual framework and state of research \\
2 & Bélanger, Carter & $\begin{array}{l}\text { Digitizing Government Interactions with Constituents: An Historical Review of E-Government Research in } \\
\text { Information Systems }\end{array}$ & 2013 \\
& & African E-Government Research Landscape & \\
3 & Fonou et al & Reflecting on e-government research: toward a taxonomy of theories and theoretical constructs \\
4 & Rana et al & Smart Governance: A Roadmap for Research and Practice & 2014 \\
5 & Scholl, Scholl & Future-oriented eGovernance: The sustainability concept in eGov research, and ways forward \\
6 & Larsson, Grönlund & The Tale of e-Government: A Review of the Stories that Have Been Told So Far and What is Yet to Come \\
7 & Ogonek & Trends of e-Government Research. Contextualization and Research Opportunities & 2014 \\
8 & Bolivar et al & E-government research in the United States & 2017 \\
9 & Snead, Wright & A meta-analysis of empirical e-government research and its future research implications \\
10 & Wirtz, Daiser & The public value of E-Government - A literature review & \\
11 & Twizeyimana, & & \\
& Andersson & Transforming the communication between citizens and government through & 2014 \\
12 & Androutsopouloua et al & AI-guided chatbots & 2016 \\
& & & 2019 \\
\hline
\end{tabular}

In their study, Estevez and Janowski (Estevez, \& Janowski, 2013) identify 5 eGovernment research dimensions, Government, Technology, Interaction, Customers and Society, analysing each one in specific elements. 78 research issues are identified in Government dimension (e.g. Alignment of strategies between central and local government, Infrastructure development, Providing broadband access). 24 research problems are identified in Technology dimension (e.g. Access in rural areas, Electronic channels for public service, Social media). 20 research problems are identified in Interaction dimension (e.g. Agreements between national-local governments, Governance of healthcare systems, Public computing centres). 19 research problems are identified in Customers dimension (e.g. Access for women, Affordable housing, Property value). 41 research problems are identified in Society dimension (e.g. Awareness of SD efforts, Hackathons for innovation, Participatory approach in developing a strategy for sustainability).

Bélanger and Carter (Bélanger, \& Carter, 2012) analyse articles that refer to the eGovernment phenomenon in general. Assessed studies present benefits and challenges which may be easier to implement, since they do not have to be tethered to a particular agency. In addition, the results are not limited to the culture and processes of a specific government agency. However, with a generic concept, subjects may have diverse perceptions and experiences when providing responses to survey questions, which could confound the results.

Fonou \& Rannyai (2014) used a qualitative technique based on online searches and literature reviews to address aspects of eGovernment development research in Africa. Amid several aspects, challenges and opportunities of eGovernment for African governments, is the most salient issue. This is aligned with the fact that most authors of eGovernment research focusing on Africa are interested in investigating the impact of the application of ICT in government (Nkomo, 2012; Agbele et al, 2012). Specific issues include Usage of ICTs in eGovernment implementation, Proposal of eGovernment strategies, Citizen roles and participation in eGovernment, Assessing state of eGovernment, Best Practices for eGovernment implementation, Analysis of eGovernment Readiness, Challenges and Opportunities of eGovernment, Implication of eGovernment on 
public policy, eGovernment initiatives undertaken, Accessibility of eGovernment services and Evaluation of Government web sites.

Rana et al., (2011) explore data that were collected from 779 research articles identified from the ISI Web of Knowledge database. The analysis of the various applications being used by the studies indicate that electronic government in general, is the most widely researched topic, followed by electronic government services. As far as specific electronic government applications are concerned, online tax filing system was researched maximum number of times. This is followed by information systems and technology, electronic filing, and broadband. Electronic or internet voting applications, website applications, internet services, information kiosks, electronic procurement, wireless technology and smartcard applications are also examined in several studies. Applications such as electronic learning, telephone channel integration, channel perception, electronic stamping, centralized customer service systems, electronic commerce, electronic tendering system, electronic complaint system, telecommunication, electronic channels, and virtual community are reviewed in few studies.

Scholl \& Scholl (2014) present and discuss an agenda for research and practice, which advances the concept of smart, open, and participatory government of the 21st century. Topics discussed include: Governmental investments (Budgeting, controlling, evaluating), Electronic government and administrative modernization (eGovernment law, simplified and reliable administrative processes etc.), Security and Safety (standards with regard to data security, privacy etc.), Infrastructure Overhaul and Ubiquitous High-speed Connectivity (gigabit Internet etc.), Electric Mobility, Participation and Collaboration (Social media and social networking uses, active and individual involvement etc.), Open Data, Big Data, Transparency of data use, Effectiveness of participatory contribution, Open government, Transparency, and Accountability.

Larsson \& Grönlund (2014) conduct a structured review of eGovernment literature investigating how various sustainability areas (social, economic, environmental and technical) are addressed. In Social category, the identify the following topics: Needs and participation, Politics and governance, Evaluation, Analysis and measurements, Values, goals and policies, Future uncertainty, Regulations, trust and security, Holistic view of organization and technology. In Economic category, they identify the following topics: Cooperation, Security \& control, Feasible plan and model, Stakeholders \& citizens, Alignment of social \& technical planning aspects, Decision making and information. In Environmental category, they identify the following topics: Decision making and information, Infrastructure \& energy, Environmental strategy, Environment as an important value for eGovernment. In Technical category, the identify the following topics: Standards and interoperability, Information preservation over generations, Holistic view, Technical infrastructure.

Ogonek's (2017) research main objective is to identify a set of topics that best represent the eGovernment research of recent years. The identified research topics range from current issues on how to increase the number of active eGovernment users by identifying the factors that lead to adoption and use of eGovernment to a more political perspective by analysing the political activity in social media to foster civic participation by direct communication through various social media products.

The first topic is eParticipation. This topic is predominantly concerned with the use of the internet and social media as communication means in electoral processes (eVoting) to foster the dialogue, engagement and active eParticipation of voters. The second topic deals with eGovernment adoption. The studies in this category identify factors that affect the acceptance and adoption of particular eGovernment services. Topic 3 is about the handling and management of governmental information. The fourth identified topic deals with eGovernment research. Topic 5, named Socio-economic Factors and Digital Divide, encompasses studies that examine the preconditions to implement eGovernment. The sixth topic adopts a rather technical perspective and describes the application of ICT systems and tools, as well as methodologies and ICT architecture for the support of eGovernment. Topic 7 examines eGovernment from an organizational point of view by addressing the implementation and management of eGovernment projects. Topic 8 embraces a policy perspective. It deals with public governance to foster openness and transparency, thus promoting the democratic process and participation by the proactive use of social media in eGovernment. Topic 9 deals with eGovernment websites. The tenth topic is about the provision of eGovernment services.

Bolivar et al., (2010) attempt to assist researchers in the development and direction of future analysis, identifying trends in terms of research and the methodology used. They identify the following research themes.

Technological innovation and modernization in public administration management: This theme focuses on the different changes in public administrations that allow greater transparency in the activities of government and public services. eGovernment programme/project evaluation and policy analysis: This topic studies the results of public programs evaluation related with initiatives of eGovernment and policies expansion of 
information technology. eParticipation and digital democracy: This theme searches emergent changes in the relationship between government and the citizen as result of eGovernment. eServices: This area discusses the transformation in the delivery of public sector services. Accountability, transparency and dissemination of information: This research theme discusses citizens' communication with governmental websites, achieving greater levels of disclosure of information to promote accountability of public managers online. Behaviour of citizens in relation to the applications of eGovernment: This topic focuses on user-centered study of the accessibility of eGovernment sites. eGovernment and personnel/human resources: This theme studies the experiences of designers of governmental Web pages; the acceptance of ICTs by public officials, as well as the challenges and efforts made by public administrations in the management of ICTs. Legislative architecture: This research focuses on administrative proceedings or any type of law that enables and encourages the adoption and implementation of eGovernment initiatives in public administrations. Intergovernmental relations: This research theme focuses on the political or institutional aspects of interagency relations between governmental units at the local, state, or national level. Digital divide and resistance barriers to eGovernment: This research item includes studies about obstacles presented by the different applications available to citizens, existing national programs to educate citizens to integrate ICTs in their daily lives, discovering its many benefits, as well as the evaluation of governmental websites to discover problems accessibility of these disabled by offering solutions. Organizational theory and behaviour: This theme researches models of innovation adoption that integrates the internal and external organizational factors, implementation factors exist in system of governance (organizational obstacles), application of business methods for the selection of investments of ICTs in the public administrations (financing challenges) as well as following the changes in the structures of public executive administrations.

Snead \& Wright (2014) explore publications to assess research efforts specific to the U.S. eGovernment environment. Articles aggregated into the general governance perspective category essentially target issues that try to understand government actions and decisions. The study presents a breakdown of the governance perspective by 10 topic areas that best represent sample authors' described targets and situational context by government level.

The predominant governance topic area is citizen interaction, which includes how citizens engage and participate in governance and access government information. The next topic is agency eGovernment adoption where research focus is primarily on agency managers/personnel acceptance, skill level, and use of agency adopted or trial use of a type of technology. These are followed by: eGovernment model testing where researchers are either develop a model or test existing proposed models; technology adoption/management where the focus is on agency efforts to adopt and manage technology; and program roles/eGovernment engagement efforts or activities where the focus is on the roles and activities agencies assume to engage in eGovernment. The rest topics are Organizational change (Agency), eFinancial transactions (Agency-citizen/business), eContracting practices (Agency-government contractors), Technology acceptance (Society) and Business engagement/participation (Agency).

Wirtz \& Daiser (2018) uncover 12 promising eGovernment research topics that carry innovative research potential. Adoption/drivers/development topic examines adoption, success factors, barriers, driver-related issues, as well as challenges with regards to eGovernment development and implementation. Acceptance/use/satisfaction topic deals with recognition and consent-based studies. Success/performance/value topic investigates the outcome of eGovernment usage. The next one, attitudes/trust studies the mindset or mental outlook, as well as the faith, that users and providers experience in relation to eGovernment. Socio-economic context group searches policy and participation issues and challenges that are related to society. The management aspects consider eGovernment from a strategic and organizational view, whereas human resource skills and development analyse personnel capacity and abilities. Information and data aspects deal with data quality and specification, as well as information requirements. Usability and complexity area explores eGovernment systems from a handling perspective. Culture-related domain examines the topic either from international or intra-group perspectives. Intergovernmental issues deal with eGovernment processes that engage multiple public sector organisations. Finally, autonomy and outsourcing area handles issues that have to do with institutional eGovernment sovereignty regarding services, processes and systems.

Twizeyimana \& Andersson (2019) organize eGovernment research in six values: improved public services; improved administrative efficiency; open government capabilities; improved ethical behaviour and professionalism; improved trust and confidence in government; and improved social value and well-being. 
Androutsopoulou et al. (2019) suggest that extensive research is required in the areas of artificial intelligence, natural language processing, machine learning and data mining technologies, in order to improve communication between government and citizens.

\section{EGOVERNMENT RESEARCH AREAS AND DIMENSIONS}

Based on aforementioned methodological approach and the review of the previous studies we classify the broader domain of eGovernment research into three areas and 20 specific research dimensions. Its dimension is characterised by specific research elements identified in literature review. The overarching areas identified both overlap and connect and in some cases even form parts of the other, but this is not visible in the table for practical reasons. The classification does not claim to be complete, but offers an approximate picture of the research field of eGovernment. Numbers inside brackets illustrate the source (Table 1) of identified research elements.

Table 2. Research Areas and Dimensions of Electronic Government

\begin{tabular}{lll}
\hline Government & Technology & Users \\
\hline eGovernment Strategy-Policy & Electronic Services & Stakeholder Interaction \\
Organisation Role & Back Office Infrastructure & User Participation \\
eGovernment Framework & Data & User Needs \\
eGovernment Assessment & Social Media & User Role \\
eGovernment Legal Framework & Applications & Digital Inclusion \\
eGovernment Research Models & Trust and Security & Impact \\
& Channels & \\
& Interoperability & \\
\hline
\end{tabular}

\section{A. Government}

This research area explores the potential policies and related practices needed for the electronic government of the future (e.g. stages of digital transformation). It gives emphasis on the organizational level of analysis, since the interests are often focused on government agencies. Typical research questions include, "how should an appropriate strategy be developed and what should it comprise", "which are the proper ways to manage eGovernment projects". Several researchers have proposed models and frameworks for the successful development, monitoring and implementation of eGovernment. Research efforts provide insightful findings and actionable recommendations for government executives and managers, with several strategic areas focused on the use of information and communication technologies. It performs qualitative meta-analyses of eGovernment frameworks and adoption studies to develop unifying theories of eGovernment adoption. Various measurement frameworks are applied to assess public sector websites' security, usability, user satisfaction and design. Lessons that can be learned from developed countries that have successfully implemented eGovernment diversification and service delivery are discussed in several papers. The following are the proposed dimensions and the relative elements for Government research area.

eGovernment Strategy-Policy dimension includes the following research issues: eGovernance mission and goals (1), eGovernment strategies (3) (10), Implication of eGovernment on public policy (3), Growth-friendly consolidation (3), Politics and governance (6) (10), Values, goals and policies (6) (7) (11), Environmental strategy (6), eGovernment Programme (8) etc.

Organisation Role dimension includes the following research issues: Program roles (1) (9), eGovernment engagement and participation of the organisation (9). Organisation's operation (1) (11), Decision making and information (6), Holistic view of organization and technology (6) (12), Modernization in Public Administration Management (8), eGovernment and personnel (8), Human Resources (8) (10), eGovernment adoption (9) (10), Technology adoption and management (9) (10), Organizational change (9) (10), Institutional change (1).

eGovernment Framework dimension includes the following research issues: Best Practices for eGovernment implementation (3), Frameworks for implementing eGovernment (3), Models and feasible plan for implementation (3), Implementation and Management of eGovernment (7), Organizational Theory and Behaviour (8) (11).

eGovernment Assessment dimension includes the following research issues: Assessing state of eGovernment (3) (10), Analysis of eGovernment Readiness (3), Evaluation of Government web sites (3) (10), Evaluation analysis and measurement metrics and indicators (6), Project Evaluation and Policy Analysis (8). 
eGovernment Legal Framework dimension includes the following research issues: eGovernment law (5), Regulations (6), Legislative Architecture (8).

eGovernment Research Models dimension includes the following research issues: Research method (7), research framework (7), research approach (7), research model (7), research model testing (9).

B. Technology

Technology is ingrained in almost every government activity today and it is perceived as an active part in transforming governance. This area studies issues like information infrastructure, which is a complex structure and involves conflict-prone matters. Information infrastructures include "hard" components (e.g. hardware and telecommunication backbones) as well as "soft" ones (e.g. applications, standards, information security, and information processes). For example, there is a need to agree on technical standards, interoperability rules at many layers and to develop and implement technology and train staff in numerous government agencies and companies to make this at all possible. Many research studies address the technical design of systems for successful implementation of eGovernment initiatives. Studies search the ways that technology and its elements affect the use and successful application of electronic services. eGovernment artefacts such as websites and eServices connecting government to its citizens are also frequently examined (Wray, \& Van Olst, 2012). The following are the proposed dimensions and the relative elements for Technology research area.

Electronic Services dimension includes the following research issues: eGovernment initiatives undertaken, electronic government services (1) (3) (4) (7) (8) (11) (e.g. e-reverse auctions, GIS, online license renewal, mobile data services eFinancial transactions (9), eContracting practices (9)), Transaction types (1) (12) (integrated services, proactive services etc.).

Back Office Infrastructure dimension includes the following research issues: Back Office Equipment (1), Usage of ICTs in eGovernment implementation (3), Telecommunication Infrastructure (4), Public Sector Information systems and technology (4), Infrastructure Overhaul (5), Ubiquitous High-speed Connectivity (5), Electric Mobility (5), Infrastructure \& energy (6), Technical infrastructure (6), IT and Systems Support for eGovernment (7), Technological Innovation (8).

Data dimension includes the following research issues: Public Data (1) (11), Open Data (5) (11), Big Data Provision (5), Information preservation over generations (6), Governmental Information Management (7) (10), eGovernment Websites (7).

Social Media dimension includes the following research issues: Social Media (1), Virtual community (4), Social media and social networking uses (5) (12), Digital Democracy (8).

Applications dimension includes the following research issues: Electronic government applications (1) (4) (7), Modular and adequate ICT support (5).

Trust and Security dimension includes the following research issues: Security and Safety (5), Trust and security (6), Security \& control (6), Privacy (7), Security (7), Trust (1) (10) (11).

Channels dimension includes the following research issues: Channels (1), channel integration (4) (12), centralized customer service systems (4), Channel Strategy (1).

Interoperability dimension includes the following research issues: Interoperability (1), Standards and interoperability (6) (7).

\section{Users}

In this research area, individual user is placed in focus. Concepts of stakeholder interaction, user participation, user needs are met, with a view towards creating new perspectives for increasing citizen involvement in eGovernment and use of eGovernment services. Studies search how should eServices be developed from a citizen perspective, what is the contribution of the citizens in this development process and what are the current perspectives and in what way do they take citizens and businesses into consideration.

eGovernment researchers incorporate a variety of factors and contexts in their research. For example, culture might have a significant impact on eGovernment implementation success. Research theories emphasize the need for continuous interaction between government organizations and the private sector in implementing eGovernment (Dlodlo, Olwal, \& Mvelase, 2012). The impact and implications of eGovernment initiatives on the structure and functioning of the public sector and the establishment of transformational change in the public sector are also discussed (Elkadi, \& Abdelsalam, 2012). Finally, efforts to prevent corruption, suggesting eGovernment strategies that standardize and clarify procedures for delivery of government services are discussed in this area (Cloete, 2012). The following are the proposed dimensions and the relative elements for Users research area.

Stakeholder Interaction dimension includes the following research issues: Partnerships (1), Cooperation (6), Stakeholders \& citizens (6), Intergovernmental Relations (8) (10) 
User Participation dimension includes the following research issues: Participation (1), Citizen roles and participation in eGovernment (3) (12), Participation and Collaboration (5) (10), Needs and participation (6), eParticipation (8), eGovernment interaction-engagement (9), participation and access (9), community (7).

User Needs dimension includes the following research issues: Citizen information needs (1), individual information services (5), information (7), Service needs (1), development needs (10).

User Role dimension includes the following research issues: Producer roles (1), Consumer roles (1), Citizen roles and participation in eGovernment (3), electronic complaint system (4), Behaviour of Citizens in Relation to the applications of eGovernment (8).

Digital Inclusion dimension includes the following research issues: Accessibility (1), Accessibility of eGovernment services (3), Demography (1), Digital Inclusion (1), Role of libraries in eGovernment (3), electronic learning (4), Digital Divide and Resistance Barriers to eGovernment (8) (10), Social tension (1), Future uncertainty (6), Socio-economic Factors and Digital Divide (7) (11), Technology acceptance (Society) (9).

Impact dimension includes the following research issues: Public value (1) (10), showcasing the effects of contributions (5), Open Government (5), Transparency (5), Accountability (5), eGovernment Adoption Factors (7) (10), Public Governance and Open Government (7), Accountability, Transparency and Dissemination of Information (8), Benefits and challenges (2), Challenges and Opportunities of eGovernment (3).

\section{CONCLUSIONS}

eGovernment is a relatively new and multidisciplinary field and demands a variety of diverse research opportunities. Ultimately, the goal of research is to persist in spite of seemingly insurmountable boundaries and advance the field for the benefit of both researchers and practitioners (Dawes, 2009). This study can be seen as the initiation point for further studies to assess how the research in eGovernment area is evolving in terms of focal points. On the basis of this study, possible future research paths will be identified for eGovernment scholars to build on and extend its body of knowledge (Ogonek, 2017), looking at underlying perspectives and approaches to eGovernment research (Heeks, \& Bailur, 2007).

The primary research question in this study focuses on research topics in the area of eGovernment. An exploration of what aspects are being explored can serve to extend the body of knowledge in the field. Insights from the past can provide direction and guidance to future studies in the field.

This study examined the field of eGovernment reviewing relative aspects at a specific point of time. A more comprehensive approach would include additional sources such as project deliverables, consulting studies, companies' reports etc. which will provide more detailed and practical insights. A future longitudinal study can be conducted to compare and contrast research practices and trends in the field of eGovernment. Further, a comparative interdisciplinary study can also be conducted to determine if patterns of research in the field of eGovernment converge with or diverge from other related disciplines, such as information systems, public administration, political and social sciences (Joseph, 2013). Additional efforts can provide an understanding of each topic area and identify research gaps, future research needs, and the development of long-term research goals and initiatives for topic areas. Overall, it is very likely that becoming more multi-disciplinary, comparative and multi-method will in the long run strengthen the theoretical capacity of eGovernment research (Ylldı, 2012). This assessment serves as the basis for a discussion of significant insights and trends related to this global phenomenon. Such insights and trends can be helpful in shaping future scholarly pursuits.

\section{ACKNOWLEDGMENT}

This paper is a result of the project "SmartEGOV: Harnessing EGOV for Smart Governance (Foundations, methods, Tools) / NORTE-01-0145-FEDER-000037", supported by Norte Portugal Regional Operational Programme (NORTE 2020), under the PORTUGAL 2020 Partnership Agreement, through the European Regional Development Fund (EFDR). 


\section{REFERENCES}

Agbele, K. K., Azeez, N. A., Abidoye, A. P., Adesina, A. O., Venter, I. M., \& Oyewole, A. S. (2012). Threats to e-government implementation in the civil service: Nigeria as a case study.

Androutsopoulou, A., Karacapilidis, N., Loukis, E., \& Charalabidis, Y. (2019). Transforming the communication between citizens and government through AI-guided chatbots. Government Information Quarterly, 36(2), 358-367.

Bélanger, F., \& Carter, L. (2012). Digitizing government interactions with constituents: an historical review of e-government research in information systems. Journal of the Association for information Systems, 13(5), 363.

Cloete, F. (2012). E-government lessons from South Africa 2001-2011: institutions, state of progress and measurement: Section II: Country perspectives on e-government emergence. The African Journal of information and communication, 2012(12), 128-142.

Cordella, A., \& Iannacci, F. (2010). Information systems in the public sector: The e-Government enactment framework. The Journal of Strategic Information Systems, 19(1), 52-66.

Dawes, S. S. (2009). Governance in the digital age: A research and action framework for an uncertain future. Government Information Quarterly, 26(2), 257-264

Dlodlo, N., Olwal, T., \& Mvelase, P. (2012). The Internet of Things in bridging the gap in municipal service delivery in South Africa

Elkadi, H. A., \& Abdelsalam, H. M. (2012). e-Alexandria 2005-2010: a multi-perspective analysis: Section II: Country perspectives on e-government emergence. The African Journal of Information and Communication, 2012(12), 143-155.

Estevez, E., \& Janowski, T. (2013). Electronic Governance for Sustainable Development - Conceptual framework and state of research. Government Information Quarterly, 30, S94-S109.

Fonou Dombeu, J. V., \& Rannyai, N. (2014). African e-government research landscape. The African Journal of Information Systems, 6(3), 2.

Heeks, R., \& Bailur, S. (2007). Analyzing e-government research: Perspectives, philosophies, theories, methods, and practice. Government information quarterly, 24(2), 243-265.

Joseph, R. C. (2013). A structured analysis of e-government studies: Trends and opportunities. Government Information Quarterly, 30(4), 435-440.

Kankanhalli, A., Zuiderwijk, A., \& Tayi, G. K. (2017). Open innovation in the public sector: A research agenda.

Larsson, H., \& Grönlund, ̊.. (2014). Future-oriented eGovernance: The sustainability concept in eGov research, and ways forward. Government Information Quarterly, 31(1), 137-149.

Nkomo, N. (2012). Implications of e-government on information delivery services. Department of Information studies, University of Zululand, South Africa.

Ogonek, N. (2017). The Tale of e-Government: A Review of the Stories that Have Been Told So Far and What is Yet to Come. In Proceedings of the 50th Hawaii International Conference on System Sciences.

Rana, N. P., Williams, M. D., Dwivedi, Y. K., \& Williams, J. (2011). Reflecting on e-government research: Toward a taxonomy of theories and theoretical constructs. International Journal of Electronic Government Research (IJEGR), 7(4), 64-88.

Rodríguez Bolívar, M. P., Alcaide Muñoz, L., \& López Hernández, A. M. (2010). Trends of e-government research: Contextualization and research opportunities.

Sarantis, D., Ben Dhaou, S., Alexopoulos, C., Ronzhyn, A., Viale Pereira, G., \& Charalabidis, Y. (2019, May). The Evolving e-Governance Curriculum: A Worldwide mapping of Education Programs. In 12th International Conference on Theory and Practice of Electronic Governance (ICEGOV2019). ACM Press.

Scholl, H. J., \& Scholl, M. (2014). Smart Governance: A Roadmap for Research and Practice. iConference. Proceedings, Berlin, March.

Snead, J. T., \& Wright, E. (2014). E-government research in the United States. Government Information Quarterly, 31(1), 129-136.

Twizeyimana, J. D., \& Andersson, A. (2019). The public value of E-Government-A literature review. Government Information Quarterly.

United Nations, (2016) government Survey 2016. Printed at the United Nations, New York, ISBN, pp.978-92.

Wirtz, B. W., \& Daiser, P. (2018). A meta-analysis of empirical e-government research and its future research implications. International Review of Administrative Sciences, 84(1), 144-163.

Wray, C., \& Van Olst, R. (2012). Enabling g-government in the Gauteng city-region: Section I: Themes and approaches to inform e-strategies. The African Journal of Information and Communication, 2012(12), 65-83.

Yıldı, M. (2012). Big questions of e-government research. Information Polity, 17(3, 4), 343-355. 